\title{
Steeply Inclined Working Face Floor Stress Distribution and Supporting Research
}

\author{
Ma Shuyin ${ }^{1,2}$ \\ ${ }^{1}$ China Coal Technology and Engineering Group Chongqing Research Institute, Chongqing, China \\ ${ }^{2}$ State Key Laboratory of the Gas Disaster Detecting Preventing and Emergency Controlling, Chongqing, China
}

Email address:

402362325@qq.com

To cite this article:

Ma Shuyin. Steeply Inclined Working Face Floor Stress Distribution and Supporting Research. Engineering and Applied Sciences. Vol. 4, No. 6, 2019, pp. 149-153. doi: 10.11648/j.eas.20190406.13

Received: November 14, 2019; Accepted: December 2, 2019; Published: December 7, 2019

\begin{abstract}
In order to obtain Stress distribution and damage law of Steeply inclined working face floor, this paper combined elastic-plastic mechanics theory to improve model of the half-infinite body model, and the three-dimensional half-infinite body model was established which comprehensively considered the stress characteristics in the strike and inclined directions of the working face, and the iterative formula of vertical stress in floors was calculated. Meanwhile, the three-dimensional stress distributions in floors with different depths were calculated by Software-MATHCAD and SUFER. The numerical simulation was applied to simulate no supporting condition and temporary supporting with Cement Based Grouting Material condition in fully-mechanized coal caving face of steeply inclined coal seam and obtained the corresponding plastic damage zone. According to the empirical formula calculated formula floor damage depth of $10.4 \mathrm{~m}$, and the application of cement grouting material was carried out on the floor, temporary support, in the working face, the lower floor heave amount reduced $28.7 \%$, in the working face, the upper floor heave amount reduced $22.4 \%$, and the supporting method can effectively control the floor damage. The results show that provided a theoretical basis for the floor management of steep coal seam working face.
\end{abstract}

Keywords: Steeply Inclined Working Face, Stress Distribution, Numerical Modeling, The Grouting Support

\section{Introduction}

The steep coal seam mining technology development level is far lower than gently inclined seam, at the same time there are a series of technical problems unresolved. Caused by coal mining stress distribution of the space around the change and to the bottom of deep, finally appear different coal floor damage [1]. In the process of mining of deeply inclined coal seam and floor strata is an important part of face space support system. Master the destruction rule of working face floor stress distribution characteristics and floor strata is the realization of steep coal seam floor security management and guarantee the important premise of mine safety production [2].

Study steeply inclined working face floor damage, many scholars only analyzes the destruction rule of working load of base plate toward the direction [3-11], ignoring the inclination direction on steep face the influence of load. Based on elastic-plastic mechanics theory and theory of three-dimensional semi-infinite body [12], steep face slab stress mechanics model is established, further concluded that the floor strata stress formula. Steeply inclined coal face slab are analysed under the joint action of trends and tendencies load state of three-dimensional stress distribution and failure regularity, and determined the floor damage depth and bottom supporting method, through the above research is of great significance to the mine working face floor management, to ensure production safety and efficiency of the working face.

\section{Working Face Floor Stress Distribution Research}

According to the knowledge of mine pressure and elastic mechanics and steep seam occurrence particularity, the half-space model was improved to tilt the three-dimensional half-space model, as shown in figure $1, \alpha \geq 45^{\circ}$. The effect of the model by $F$ concentrated force, and the model by the normal component of $F_{1}$, along the $\mathrm{Y}$ axis orientation of component $F_{2}$. Due to the large face steep dip Angle of the special reason, tendency of component is more and more big, 
the rock mass by the force of law to the tendency to component and component interaction (as shown in figure 1).

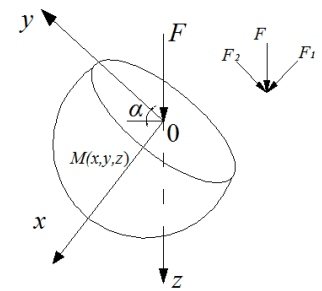

Figure 1. Diagram of the concentrated force in the three-dimensional semiinfinite space.

As A bit of $M(x, y, z)$ vertical stress in the $\sigma_{z}$ floor rock mass for the law to the component and the tendency of component the result of joint action. The role of discussion method to the first component $F_{1}$ :

$$
\sigma_{z 1}=\frac{3 F z^{3}}{2 \pi\left(x^{2}+y^{2}+z^{2}\right)^{5 / 2}}
$$

Within an arbitrary partition, stress coefficient in the $\mathrm{X}, \mathrm{Y}$ axis direction changes as shown in formula (2).

$$
\begin{array}{r}
q(x)=q(\xi)=\frac{\eta-\eta_{1}}{\eta_{2}-\eta_{1}}\left(\xi_{2}-\xi_{1}\right)+\xi_{1} \\
p(y)=p(\eta)=\frac{\xi-\xi_{1}}{\xi_{2}-\xi_{1}}\left(\eta_{2}-\eta_{1}\right)+\eta_{1}
\end{array}
$$

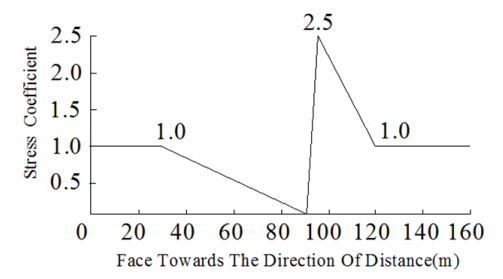

a. Face towards the direction of stress distribution
Type: $\xi, \eta$, respectively the $\mathrm{X}, \mathrm{Y}$ direction stress coefficient, so the first $j$ partition load stress affect the action of the floor is:

$$
\begin{aligned}
& \sigma_{z 1}^{(j)}(x, y, z)=-\frac{3 z^{3}}{2 \pi} \int_{\xi_{1 j}}^{\xi_{2 j}} \int_{\eta_{1 j}}^{\eta_{2 j}} \\
& \frac{\left[\frac{\eta-\eta_{1 j}}{\eta_{2 j}-\eta_{1 j}}\left(\xi_{2 j}-\xi_{1 j}\right)+\xi_{1 j}\right]+\left[\frac{\xi-\xi_{1 j}}{\xi_{2 j}-\xi_{1 j}}\left(\eta_{2 j}-\eta_{1 j}\right)+\eta_{1 j}\right]}{\left[(x-\xi)^{2}+(y-\eta)^{2}+z^{2}\right]^{5 / 2}} d \eta d \xi
\end{aligned}
$$

Similarly, discuss the tendency of component $F_{2}$ function:

$$
\sigma_{z 2}=\frac{F x z^{2}}{\pi\left(x^{2}+y^{2}+z^{2}\right)^{5 / 2}}
$$

The first $i$ partition load stress affect the action of the floor is:

$$
\begin{aligned}
& \sigma_{z 2}^{(i)}(x, y, z)=-\frac{3 z^{3}}{2 \pi} \int_{\xi_{1 i}}^{\xi_{2 i}} \int_{\eta_{1 i}}^{\eta_{2 i}} \\
& \frac{\left[\frac{\eta-\eta_{1 i}}{\eta_{2 i}-\eta_{1 i}}\left(\xi_{2 i}-\xi_{1 i}\right)+\xi_{1 i}\right]+\left[\frac{\xi-\xi_{1 i}}{\xi_{2 i}-\xi_{1 i}}\left(\eta_{2 i}-\eta_{1 i}\right)+\eta_{1 i}\right]}{\left[(x-\xi)^{2}+(y-\eta)^{2}+z^{2}\right]^{5 / 2}} d \eta d \xi
\end{aligned}
$$

To simplify the will base on the load, as shown in figure 2 (working in $x=90 \mathrm{~m}$ place, inclined position from $y=30 \mathrm{~m}$ to $y=160 m$ ).

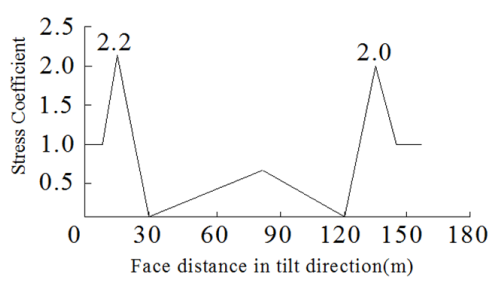

b. The stress distribution of face tilt direction

All partitions in the floor strata under the influence of the load stress is:

$$
\sigma_{z}(x, y, z)=\sum_{i=1, j=1}^{9} \sigma_{z}^{i, j}(x, y, z)
$$

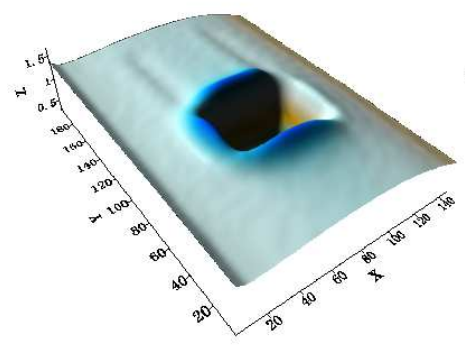

Bottom $10 \mathrm{~m}$
Using MATHCAD software to calculate the coefficient of different depth of floor stress and combining Sufer charting software, it is concluded that the three dimensional state under different depth of floor stress coefficient contour stereogram, $\mathrm{Z}$ axis stress coefficient, $\mathrm{Y}$ axis working face, the $\mathrm{X}$-axis represents the working face. As shown in figure 3.

Figure 3. The three-dimensional of contours of the stress coefficient of the floor. 
By figure 3 available:

(1) Floor below $10 \mathrm{~m}, 25 \mathrm{~m}$ in depth of the maximum stress coefficient were $1.68,1.17$. Maximum stress coefficient at coal face in front of the $0 \sim 23 \mathrm{~m}, 0 \sim 29 \mathrm{~m}$ range. On both sides of the working face and goaf and both sides have different degree of stress concentration, the goaf under stress is greater than the upper side. When distance floor below $40 \mathrm{~m}$ in the depth of the stress concentration area basically does not exist, but there are a range of unloading zones, the minimum stress coefficient of 0.421 ;

(2) With bottom depth increase, the three-dimensional state of floor strata stress coefficient of each isoline stereogram funnel in high stress area increases gradually, but the stress coefficient decreases, eventually tend to 1; Low stress area decreases, but the stress coefficient is increased gradually, eventually tend to be 1 .

\section{Face Plate Destruction In-depth Analysis}

Due to coal mining floor rock mass stress secondary distribution further causes damage on the floor. According to the floor rock mass stress distribution, take along the working direction of the tilt section as the calculation section [13], According to the principle of Saint Venant, about the way of working face tendency of abutment pressure static equivalent force system replace, combining with Mohr-Coulomb criteria for working face floor rock mass maximum damage depth $h$ [14-15].

$$
h=\frac{(n+1) H}{2 \pi}\left(\frac{2 \sqrt{k}}{k-1}-\arccos \frac{k-1}{k+1}\right)-\frac{R_{c}}{\gamma(k-1)}
$$

Type: $n$ is the maximum stress concentration factor; $H$ is mining depth; $k=(1+\sin \phi) /(1-\sin \phi), \phi$ is internal friction Angle of rock mass; $R_{\mathrm{c}}$ is unidirectional compressive strength of rock mass; $\gamma$ is rock mass density.

Mine 3232 (3) working face maximum mining depth is $495 \mathrm{~m}$, the floor rock mass unidirectional compressive strength is $2.9 \mathrm{MPa}$, internal friction Angle of rock mass is $42^{\circ}$, rock mass density is $0.025 \mathrm{MN} / \mathrm{m}^{3}$, the calculated formula floor damage depth of $10.4 \mathrm{~m}$.

\section{The Numerical Simulation}

\subsection{The Establishment of the Model}

Due in the process of mining steep stress distribution and plastic damage, using FLAC3D built along the mine 3232 (3) working face toward the direction of advance of FLAC3D numerical model. Face to the length of $980 \mathrm{~m}$, length of $124 \mathrm{~m}$, the total height is $520 \mathrm{~m}$, an average of $495 \mathrm{~m}$ buried deeply. To illustrate the overburden force of the model, basic roof applying vertical load $12.5 \mathrm{MPa}$. In the model the main research floor rock mass affected by the process of working face advancing and produce the plastic failure mechanism. Mechanical characteristic parameters of coal seam roof and floor are shown in table 1.

Table 1. Characteristic parameters of coal seam roof and floor mechanics.

\begin{tabular}{lllllll}
\hline The lithology & Density/(kg. $\left.{ }^{-3}\right)$ & $\begin{array}{l}\text { Bulk modulus } \\
(\mathbf{G P a})\end{array}$ & $\begin{array}{l}\text { Modulus of rigidity } \\
(\mathbf{G P a})\end{array}$ & $\begin{array}{l}\text { Angle of internal } \\
\text { friction }\left({ }^{\circ}\right)\end{array}$ & $\begin{array}{l}\text { Cohesive strength } \\
(\mathbf{M P a})\end{array}$ & $\begin{array}{l}\text { Tensile strength } \\
(\mathbf{M P a})\end{array}$ \\
\hline Medium coarse sandstone & 2500 & 8.2 & 7.2 & 30 & 3.8 & 4.2 \\
Fine sandstone & 2400 & 7.8 & 7.1 & 31 & 3.9 & 4.1 \\
Mudstone & 2200 & 5.9 & 5.2 & 33 & 2.1 & 1.4 \\
Coal & 1470 & 2.2 & 2.0 & 28 & 1.8 & 0.8 \\
Mudstone & 2200 & 5.9 & 5.2 & 33 & 2.1 & 1.4 \\
Siltstone & 2530 & 8.3 & 7.4 & 35 & 3.1 & 3.4 \\
Post stone & 2500 & 10.6 & 9.0 & 35 & 4.5 & 3.8 \\
Medium coarse sandstone & 2510 & 8.3 & 7.4 & 31 & 3.6 & 3.2 \\
\hline
\end{tabular}

\subsection{Analysis of Surrounding Rock Floor Without Supporting Condition}

The plastic zone along the working face sloping direction as shown in figure 4 , By figure $4 \mathrm{a}$, the distribution of lateral abutment pressure caused by the plastic on both ends of the working face and level of working face are similar, but different on both ends of the plastic zone damage, on both sides of the mass media has a stress concentration. After coal extraction, face the floor rock mass unloading zone and form a larger plastic damage area in floor rock mass, the plastic damage area show the middle and lower slightly larger than the upper asymmetry, in the working face was described, and the lower plastic damage more serious. The figure 5a shows that steep face plate of displacement is vertical displacement and horizontal displacement of the fitting, the show floor and floor heave, plastic deformation and destruction in serious area of floor heave of bottom slip, should increase the floor rock mass strength, increase the cohesion of rock mass, to prevent the destruction of the bottom slip to support, coal winning machine equipment damage. 


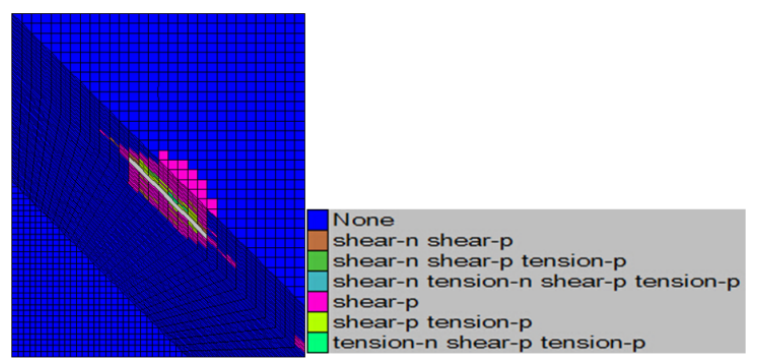

a. Support before

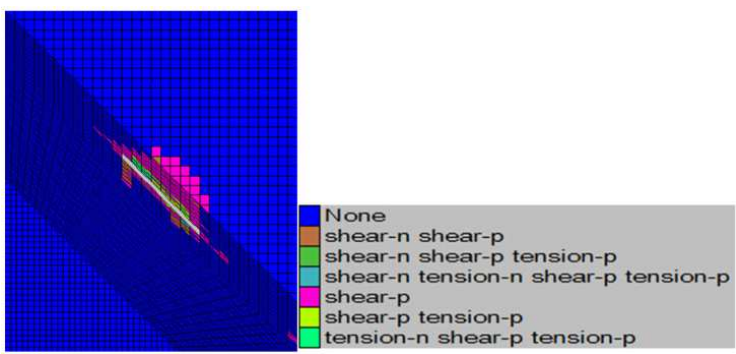

b. After supporting

Figure 4. Working face floor support before and after the distribution of plastic zone.

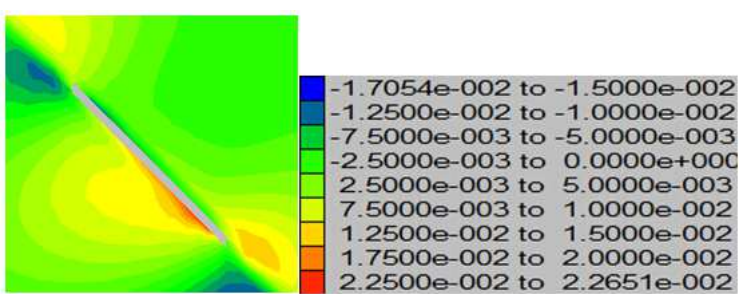

a. Support before

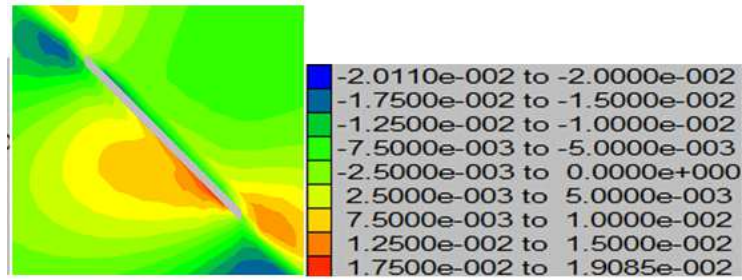

b. After supporting

Figure 5. Before and after the working face floor support displacement.

\subsection{The Scheme Determination of Floor Grouting}

Accord with Mohr-Coulomb criterion floor rock mass:

$$
\tau=c+\sigma_{n} \tan \phi
$$

Type: $c$ is the cohesion of rock mass; $\sigma_{n}$ is the normal stress shearing surface; $\phi$ is the internal friction Angle of rock mass. In order to prevent steep face plate destruction to the harm of production equipment and affect production safety. Coal mine grouting reinforcement method, increase the cohesion of $c$ rock to improve the overall floor rock mass strength further control bottom plastic damage.

Theoretical calculation of the maximum damage depth of $10.4 \mathrm{~m}$ floor and floor unsupported state numerical simulation analysis on motherboard damage depth of $11.2 \mathrm{~m}$, the gap between the two groups of damage depth of $0.8 \mathrm{~m}$ belongs to within a reasonable range. Considering the situation working face, the injection of cement grouting reinforcement material site selection in the coal wall slab depth of $10.4 \mathrm{~m}$.

\subsection{Floor Bolting After the Analysis of the Surrounding Rock}

After working face according to the requirements for supporting, again using numerical simulation software to calculate and compared with without supporting conditions. According to figure $4 \mathrm{~b}$, the damage zone and the bottom floor plastic damage depth is reduced, after this case bottom support, increase the cohesion of rock mass and the strength of the rock mass. At the same time, under the influence of mining stress difference before and after mining reduced, this for unloading area floor damage under effective control; By figure 5b, Coal floor in vertical and horizontal direction of fitting displacement decrease obviously, this kind of situation that floor damage amount is reduced, by supporting amount of drum at the bottom of the $322.5 \mathrm{~mm}$ to $260.5 \mathrm{~mm}$.

\section{Field Application Effect}

Mine 3232 (3) working face length of $124 \mathrm{~m}$, the mine coal seam dip Angle $45^{\circ}$ on average. As shown in figure 6, 7, during working face floor, floor in accordance with the plan calls for injection after grouting reinforcement material, middle and lower support before the sole drum quantity is $330.5 \mathrm{~mm}$, after supporting is $235.5 \mathrm{~mm}$, floor heave amount reduced $28.7 \%$. Amount of working face in the middle and upper part of the sole drum is $275 \mathrm{~mm}$, after supporting is $213.5 \mathrm{~mm}$, floor heave amount reduced $22.4 \%$.

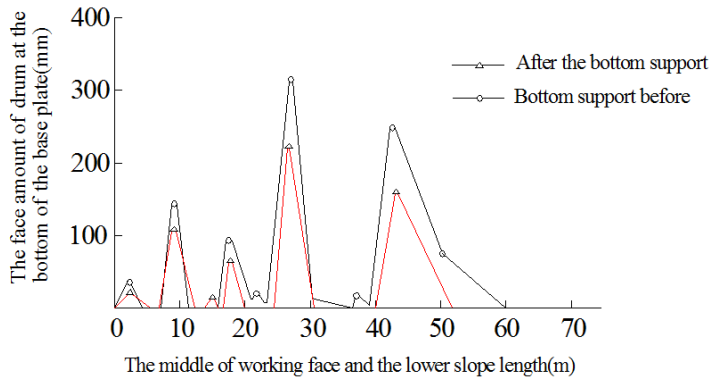

Figure 6. Before and after the working face Middle and lower part floor support displacement.

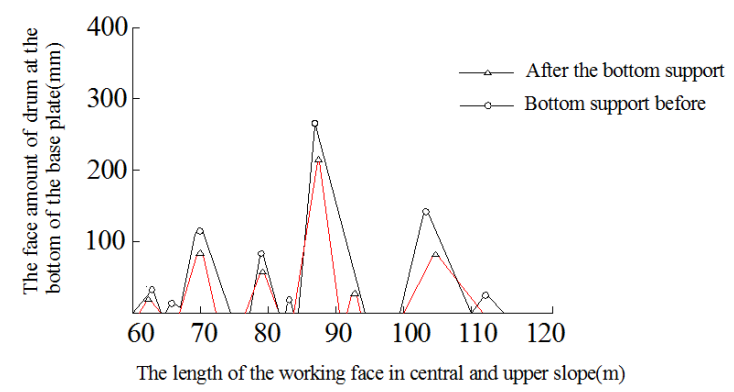

Figure 7. Before and after the working face Middle and upper part floor support displacement. 


\section{Conclusion}

(1) Through the establishment of steeply inclined coal face slab stress model, it is concluded that the three-dimensional state of face slab vertical stress contour stereogram, Face slab depth can be drawn from the high stress area increases gradually, but the stress coefficient decreases, and eventually tend to 1; Although the stereogram display low stress area decreases, but the stress coefficient is gradually increases and eventually tend to be 1 .

(2) According to the principle of Saint Venant, Mohr-Coulomb standards, it is concluded that the mine 3232 (3) working face slab maximum damage depth of $10.4 \mathrm{~m}$. And deep in the bottom of $10.4 \mathrm{~m}$ for grouting material support, this kind of supporting method can effectively control the floor damage and slippage and makes the floor damage amount is reduced, and from supporting amount of floor heave at the bottom of the $322.5 \mathrm{~mm}$ to $260.5 \mathrm{~mm}$.

\section{Acknowledgements}

The study was supported by the National Science and Technology Major Project of the Ministry of Science and Technology of China (No. 2016Z; 5043005-002).

\section{References}

[1] MENG Xiang-rui, XU Cheng-hui, GAO Zhao-ning, et al. Stress distribution and damage mechanism of mining floor [J]. Journal of China Coal Society, 2010, 35 (11): 1832-1836.

[2] LIU De-jun. The stress distribution of the goaf and its relationship of water inrush [J]. Safety in Coal Mines, 1988, 7: 35-39.

[3] LINFeng. Equivalent-material simulation and analysis of stress distribution over seam floors [J]. Journal of Anhui University of Science and Technology, 1990, 10 (3): 19-28.

[4] CAO Shu-gang, XU Guang-ming, CHEN Lin-dun. Panel roadway floor stress distribution [J]. Ground Pressure and Strata Control, 1993, 10 (Supp): 177-180.
[5] ZHU Shu-yun, JIANG Zhen-quan, YAO Pu, et al. Application of analytic method in calculating floor stress of a working face [J]. Journal of Mining and Safety Engineering, 2007, 24 (2): 191-195.

[6] ZHANG Hua-lei, WANG Lian-guo. Computation of mining induced floor additional stress and its application [J]. Journal of Mining and Safety Engineering, 2011, 28 (2): 288-293.

[7] WANG Lian-guo, HAN Meng, WANG Zhan-sheng et al. Stress distribution and damage law of mining floor [J]. Journal of Mining and Safety Engineering, 2013, 30 (3): 317-322.

[8] LI Xiang-yang, LI Jun-ping, ZHOU Chuang-bing, Xiang wen-fei et al. Comparative study on numerical simulation and similarity simulation of overburden deformation in abandoned stope [J]. Rock and Soil Mechanics, 2005, 26 (12): 1907-1912.

[9] GAO Zhao-ning, MENG Xiang-rui. Study on Deformation and Fracturing Characteristics of Seam Floor under Mining Influence $[\mathrm{J}]$. mining safety \& environmental protection. 2010, 37 (3): 17-20.

[10] ZHANG Yong etc. Damage and Slip Mechanism of Floor in Longwall Mining on the Strike of Steep and Thick Coal Seam [J]. Coal Science and Technology, 2013, 41 (10): 9-12.

[11] XUN Yan-chun, YANG Yang etc. Applicability Analysis on Statistical Formula for FailureDepth of Coal Seam Floor in Deep Mine [J]. Coal Sci-ence and Technology, 2013, 41 (9): 129-132.

[12] YANG Sheng-li, ZHAO Bin, LI Liang-hui. Coal wall failure mechanism of longwall working face with false dip in steep coal seam [J]. Journal of China Coal Socity. 2019, 44 (2): 367-376.

[13] WANG Nan, ZHENG Shangshang, LI Shanshan, KONG Dezhong. Stability Analysis of End Face Roof of Steep Inclined Coal Seam [J]. Safety in Coal Mines, 2019, 50 (6): 235-239.

[14] CHENG Wei-min, SUN Lu-lu, WANG Gang et c. Similar material simulation test of steep-inclined extra-thick coal seam [J]. Journal of Mining \& Safety Engineering. 2016, 33 (3): 387-392.

[15] ZHANG Pingsong, WU Jiwen, LIU Shengdong. Study on dynamic observation of coal seam floor's failure law $[\mathrm{J}]$. Chinese Journal of Rock Mechanics and Engineering, 2006, 25 (Sup 1): 3009-3013. 